\title{
Removal of Iron from Molten Recycled Aluminum through Intermediate Phase Filtration
}

\author{
Humberto Lopes de Moraes ${ }^{1, *}$, José Roberto de Oliveira ${ }^{2}$, Denise Crocce Romano Espinosa ${ }^{1}$ \\ and Jorge Alberto Soares Tenório ${ }^{1}$
}

${ }^{1}$ Department of Metallurgical and Materials Engineering, Polytechnic School, University of São Paulo,

Av. Prof. Mello Moraes 2463, São Paulo-SP, 05508-900, Brazil

${ }^{2}$ Centro Federal de Educação Tecnológica do Espírito Santo-CEFETES. Av. Vitória,

1729 Vitória, ES, 29040-780, Brazil

Aluminum is one of the most versatile materials used in foundry practice; however, iron is one of the most troublesome impurities in aluminum cast materials. During the solidification of aluminum alloys, iron promotes the formation of intermediate phases, which may damage the properties of the final product. In secondary aluminum industries, iron contamination caused by high amounts of iron scrap is always possible. Consequently, the aim of this work was to study the most efficacious method and conditions for the removal of iron from molten aluminum through ceramic filters. The materials studied were based on the AA308 and AA356 aluminum alloys with iron additions. The variables of this work were chemical composition, temperature and the type of filter. The results showed that iron could be efficiently removed through the use of manganese and silicon followed by the decrease of the temperature at which the intermediate phases crystallize. [doi:10.2320/matertrans.47.1731]

(Received January 24, 2006; Accepted May 16, 2006; Published July 15, 2006)

Keywords: aluminum alloys, iron removal, recycling

\section{Introduction}

Iron is one of the most damaging impurities in the production of cast metal with good mechanical properties, using permanent and sand molding. Iron along with aluminum and other alloying elements, such as manganese, copper, magnesium, and silicon, produce intermediate phases, which are damaging to the mechanical properties of the final product.

Iron contamination may occur in the bath in secondary aluminum industries, resulting from the iron scrap mixed with aluminum scrap. Additionally, aluminum scrap can itself contain high iron concentration, from aluminum production by a die-casting molding process. In order to minimize the contamination problem caused by steel scrap, aluminum industries implement classification processes prior to the melting step, such as manual sorting, magnetic separating, eddy current separating, trommel screening, and the use of an air knife, according to the production process.

Another alternative that bypasses the iron contamination problem is to dilute the aluminum bath with primary aluminum; having an iron content lower than the bath. This alternative requires a cost for analysis of primary aluminum compared to recycled aluminum.

During the solidification step of aluminum cast alloys, the primary phase is usually formed by aluminum. Other constituents of the alloy disperse into the remaining region between the grains of the primary phase. Contamination with iron may cause a change in solidification, with the appearance of primary phases containing iron prior to the crystallization of aluminum grains. Formed before aluminum, these phases present the possibility of free growth,

*Graduated Student, Department of Metallurgical and Materials Engineering, Polytechnic School, University of São Paulo generating coarse crystals in the liquid phase.

Iron removal technique by precipitation of intermediate phases followed by filtering would allow the use of aluminum scrap from any source, independent of its initial iron content, in applications requiring low iron content, such as permanent or sand molding cast alloys.

Cast alloys usually use silicon to reduce liquid viscosity. Aluminum-iron-silicon ${ }^{1)}$ is the base system used to study the solidification path of cast aluminum alloys contaminated with iron. However, alloys in the aluminum-iron-silicon system still show a relatively high solubility of iron in the liquid phase, even after removal of primary crystals that contain iron. Thus, an even greater reduction of iron is necessary in the primary crystallization field of aluminum and in iron solubility in the liquid phase. This effect can be achieved by adding manganese, transforming the ternary aluminum-iron-silicon system into the quaternary aluminumiron-manganese-silicon system. ${ }^{2)}$

Hence, the removal of iron is primarily attained by adding an alloying element, manganese in this case, which changes the solidification path of alloys, favoring the precipitation of intermediate phases containing iron and also reducing the residual content of iron in the liquid phase to acceptable levels for cast alloys. Molten metal is maintained at an intermediate temperature between the formation of the intermediate phase and the appearance of aluminum. Separation of solid phase from liquid phase occurs by filtering under this condition.

Considering the above reported information, this work aims to study the iron removal from molten aluminum by filtering iron-rich intermediate phases. Compositions similar to the 308 and 356 series alloys were studied. The variables of this work were: chemical composition, filtering temperature, and type of filter. 
Table 1 Chemical composition (mass\%) of E, 356 and 308 series.

\begin{tabular}{lcccc}
\hline \multicolumn{1}{c}{ Alloy } & $\mathrm{Si}$ & $\mathrm{Fe}$ & $\mathrm{Cu}$ & $\mathrm{Mn}$ \\
\hline E15F3M & 0.25 & 1.45 & 1.00 & 0.30 \\
E5F7M & 0.25 & 1.45 & 1.00 & 0.75 \\
E12S15F1M & 12.0 & 1.50 & 1.00 & 1.00 \\
E95S15F15M & 9.50 & 1.50 & 2.50 & 1.50 \\
E95S10F15M & 9.50 & 1.00 & 3.00 & 1.50 \\
3081F & 5.50 & 1.00 & 3.35 & 0.14 \\
3082F3M & 5.50 & 2.00 & 3.70 & 0.30 \\
3081F7M & 5.50 & 1.00 & 3.10 & 0.70 \\
3561F & 7.00 & 1.00 & 0.00 & 0.0095 \\
3561F6M & 7.00 & 1.00 & 0.00 & 0.60 \\
\hline
\end{tabular}

\section{Materials and Methods}

Three assay series were performed. The first series corresponded to an experimental alloy (E series) and in the others the materials studied were based on 356 and 308 alloys made from aluminum-silicon and aluminum-copper-silicon ${ }^{3)}$ system, respectively. Table 1 exhibits the compositions of alloys prepared in this study. All the compositions in this study are in mass \%. The following methods were used in this study: melting and filtering tests, sample preparation for chemical analyses, metallography, Scanning Electron Microscopy (SEM).

\subsection{Melting and filtering}

Alloy preparation was performed by melting the aluminum, then adding the alloy elements. Standard grade aluminum was used, while electrolytic copper and manganese, metallurgical grade silicon were used and low carbon steel was used as iron source. The total weight of the charge in all tests was $2.5 \mathrm{~kg}$.

A laboratory-scale electric furnace was adapted for melting of the aluminum with alloying elements at $850^{\circ} \mathrm{C}$. The system was held for a 2-hours interval following the stabilization of the temperature. Graphite crucibles with $150 \mathrm{~mm}$ (diameter) and $200 \mathrm{~mm}$ (height) and capacity of $3.0 \mathrm{~kg}$ were used.

The ceramic filter was heated at $750^{\circ} \mathrm{C}$ in another furnace. This filter was assembled on the top of a graphite crucible with the above-mentioned dimensions. The filter was adapted at a fixed height for all experiments. Ceramic foam-type filters with 1.15 and $0.78 \mathrm{~mm}$ average pore diameter (20 and 30 pores per inch) were used.

The bath was then cooled to the filtering temperature at a mean cooling rate of $4.4^{\circ} \mathrm{C} / \mathrm{min}$. At the filtering temperature, the bath was held for a period of 30 minutes. Subsequently, the molten metal was cast into the pre-heated filter. Figure 1 shows a schematic diagram of the filtering process.

In all experiments, the bath temperatures were measured by a chromel-alumel thermocouple. Table 2 exhibits the experimental conditions. Filtering temperature varied in every alloy.

\subsection{Sample preparation for chemical analysis}

The contents of iron, manganese, and copper were analyzed before and after the filtering step by using atomic

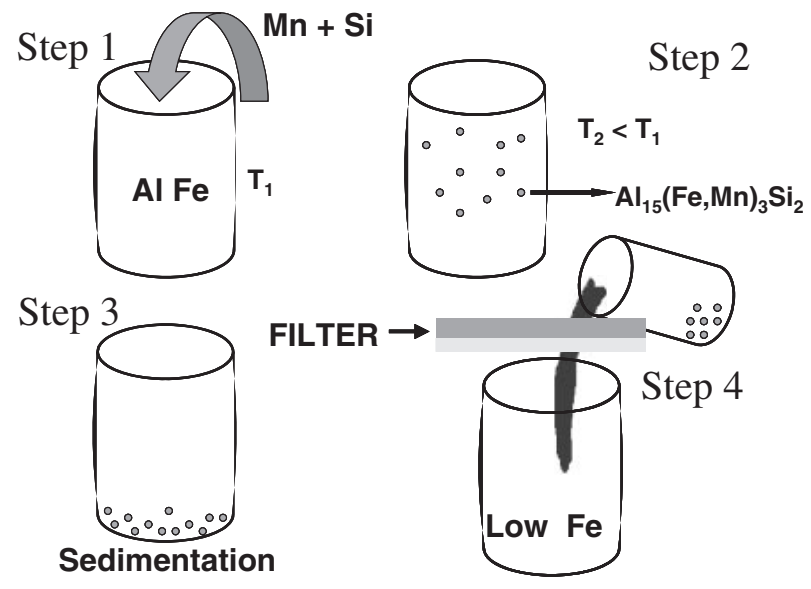

Fig. 1 Schematic diagram of the filtering process.

Table 2 Test conditions of E, 308 and 356 series.

\begin{tabular}{cccc}
\hline Test & Alloy & $\begin{array}{c}\text { Filter } \\
(\mathrm{ppi})\end{array}$ & $\begin{array}{c}\text { Temp. } \\
\left({ }^{\circ} \mathrm{C}\right)\end{array}$ \\
\hline 01 & E15F3M & 20 & 665 \\
02 & E15F7M & 30 & 665 \\
03 & E15F3M & 20 & 660 \\
04 & E12S15F10M & 20 & 605 \\
05 & E1215F10M & 20 & 625 \\
06 & E95S15F15M & 30 & 605 \\
07 & E95S10F15M & 20 & 610 \\
08 & E95S10F15M & 20 & 605 \\
09 & $3561 F$ & 20 & 645 \\
10 & $3561 F 6 M$ & 20 & 640 \\
11 & $3082 F$ & 20 & 635 \\
12 & $3081 F$ & 20 & 625 \\
13 & $3081 F 7 M$ & 20 & 618 \\
\hline
\end{tabular}

absorption spectrophotometry in all experiments. Before the filtering step, molten metal samples for analysis were collected with a stainless steel spoon. The metal was cast in a steel mold and each sample weighed 20 to $25 \mathrm{~g}$. After solidification, each sample was removed and machined, and then the chips were collected for chemical analysis.

\subsection{Metallography}

Samples from the following materials were collected after the casting and filtering steps for metallography: filtered material, filter with retained material, and material sedimented at the bottom of the crucible. The prepared samples were submitted for observation under optical microscope in order to perform identification of present phases.

\subsection{Scanning Electron Microscopy (SEM)}

Samples were taken from the material sedimented at the bottom of the crucible and from the filtered material for observation under scanning electron microscope. The aim of this step was to identify the intermediate phases that remained in the sediment at the bottom of the crucible and the phases presented in the filtered metal. 
Table 3 Results of E series.

\begin{tabular}{lccccc}
\hline \multicolumn{1}{c}{ Alloy } & $\begin{array}{c}\text { Filter } \\
(\mathrm{ppi})\end{array}$ & $\begin{array}{c}\text { Temp. } \\
\left({ }^{\circ} \mathrm{C}\right)\end{array}$ & $\begin{array}{c}\text { Initial Fe } \\
(\%)\end{array}$ & $\begin{array}{c}\text { Final Fe } \\
(\%)\end{array}$ & $\begin{array}{c}\text { Removal of Fe } \\
(\%)\end{array}$ \\
\hline E15F3M & 20 & 665 & 1.28 & 1.30 & 0.0 \\
E15F3M & 20 & 660 & 1.25 & 1.28 & 0.0 \\
E15FM7M & 30 & 665 & 1.29 & 1.30 & 0.0 \\
E15F12S10M & 20 & 605 & 1.32 & 0.40 & 69.7 \\
E15F12S10M & 20 & 625 & 1.30 & 0.48 & 63.0 \\
E15F95S15M & 30 & 605 & 1.34 & 0.25 & 83.0 \\
E10F95S15M & 20 & 610 & 1.14 & 0.41 & 64.0 \\
E10F95S15M & 20 & 605 & 0.98 & 0.18 & 82.0 \\
\hline
\end{tabular}

\section{Results and Discussion}

The results obtained in the filtering process of aluminum alloys will be presented and discussed in this chapter. The procedure can be divided in two steps. In the first step, E series, additions of silicon, manganese, and copper were performed. The effects of the same parameters were studied for two commercial alloys from these results.

\subsection{E series}

This series was designed to assess the behavior of silicon, copper and manganese in the formation of the intermediate phases.

Table 3 shows the results of the filtering experiments with alloys of $\mathrm{E}$ series. There was no iron removal during the filtering of the E15F alloy. Filtering the material was not possible by temperature reduction. Hence, probably no formation of any intermediate phase containing iron occurred even in the presence of alloying elements, such as $0.7 \%$ manganese and $1.0 \%$ copper. The content of silicon in this alloy was $0.25 \%$. Despite the system having multi-components, the observation of the aluminum-iron-silicon system indicates that silicon, in this range, does not induce the precipitation any intermediate phase containing iron.

On the other hand, the removal of iron was confirmed with the E15F12S alloy, from 1.32 to $0.40 \%$. The analysis of the aluminum-iron-silicon ternary phase diagram indicates that the alloy is placed in the field where the primary phase is $\mathrm{Al}_{5} \mathrm{FeSi}$.

It is noteworthy that, from the aluminum-iron-siliconmanganese pseudo-ternary system, the addition of manganese in the E15F12S alloy causes a reduction in the primary crystallization field of aluminum, due to the appearance of a $\mathrm{Al}_{15}(\mathrm{Fe}, \mathrm{Mn})_{3} \mathrm{Si}_{2}$-type intermediate phase field between the primary aluminum phase and the $\mathrm{Al}_{5} \mathrm{FeSi}$ intermediate phase. According to Flores et al. ${ }^{4)}$ the growth of $\mathrm{Al}_{15}(\mathrm{Fe}, \mathrm{Mn})_{3} \mathrm{Si}_{2}$ is controlled by diffusion. Consequently, the mean particle size is a function of the holding time.

Filtering temperatures in the experiments of E10F95S15M were 610 and $605^{\circ} \mathrm{C}$, as can be seen in Table 3. In these cases, the reduction in the temperature caused an increase in the filtering efficiency, which means that a lower final content of iron was reached. The effect of manganese additions and reduction of temperature was also reported in the literatures. ${ }^{3,5)}$

Iron removal in the experiments with E15F95S and
Table 4 Manganese concentrations before and after filtering.

\begin{tabular}{ccccc}
\hline Alloy & $\begin{array}{c}\text { Filter } \\
(\mathrm{ppi})\end{array}$ & $\begin{array}{c}\text { Temp. } \\
\left({ }^{\circ} \mathrm{C}\right)\end{array}$ & $\begin{array}{c}\text { Initial Mn } \\
(\%)\end{array}$ & $\begin{array}{c}\text { Final Mn } \\
(\%)\end{array}$ \\
\hline E15F95S & 30 & 605 & 1.60 & 0.20 \\
E15F95S & 20 & 605 & 1.45 & 0.12 \\
\hline
\end{tabular}

Table 5 Copper concentrations before and after filtering.

\begin{tabular}{ccccc}
\hline Alloy & $\begin{array}{c}\text { Filter } \\
(\mathrm{ppi})\end{array}$ & $\begin{array}{c}\text { Temp. } \\
\left({ }^{\circ} \mathrm{C}\right)\end{array}$ & $\begin{array}{c}\text { Initial Cu } \\
(\%)\end{array}$ & $\begin{array}{c}\text { Final Cu } \\
(\%)\end{array}$ \\
\hline E1F95S & 30 & 605 & 2.25 & 2.52 \\
E1F95S & 20 & 605 & 2.90 & 3.10 \\
\hline
\end{tabular}

Table 6 Results of 308 and 356 series alloys.

\begin{tabular}{lccccc}
\hline \multicolumn{1}{c}{ Alloy } & $\begin{array}{c}\text { Filter } \\
(\mathrm{ppi})\end{array}$ & $\begin{array}{c}\text { Temp. } \\
\left({ }^{\circ} \mathrm{C}\right)\end{array}$ & $\begin{array}{c}\text { Initial Fe } \\
(\%)\end{array}$ & $\begin{array}{c}\text { Final Fe } \\
(\%)\end{array}$ & $\begin{array}{c}\text { Removal of Fe } \\
(\%)\end{array}$ \\
\hline 3561F & 20 & 645 & 1.00 & 0.91 & 9 \\
$3561 \mathrm{~F} 6 \mathrm{M}$ & 20 & 640 & 1.12 & 0.37 & 67 \\
$3082 \mathrm{~F}$ & 20 & 635 & 2.18 & 1.09 & 50 \\
$3081 \mathrm{~F}$ & 20 & 625 & 0.83 & 0.45 & 46 \\
$3081 \mathrm{~F} 7 \mathrm{M}$ & 20 & 618 & 1.00 & 0.21 & 79 \\
\hline
\end{tabular}

E10F95S alloys showed the efficiency in 64-83\% range. Silicon, copper and manganese were added to this alloy. Grigonenko et al. ${ }^{3)}$ studied the removal of iron from aluminum-silicon-copper alloys and a reduction from 1.5$2.2 \%$ to less than $0.5 \%$ was observed.

The aluminum-iron-silicon ternary phase diagram indicates that these alloys are placed in the primary aluminum field, very close to the eutectic trough. However, by using the aluminum-iron-manganese-silicon pseudo-binary system, ${ }^{2)}$ one can note that the addition of manganese in the alloys of the aluminum-iron-silicon system causes a reduction in the primary crystallization field of aluminum. Thus, these alloys fall into the $\mathrm{Al}_{15}(\mathrm{Fe}, \mathrm{Mn})_{3} \mathrm{Si}_{2}$ primary phase field.

Chemical analyses of manganese before and after the filtering step show the participation of manganese in the formation of the intermediate phase (Table 4). The analysis of copper content before and after the filtering step shows no direct participation of copper, because the contents remained approximately constant (Table 5).

A somewhat increase in the final contents of copper are observed and it should be caused by the segregation of the intermediate phases, which are rich in silicon, iron, and manganese.

\subsection{Experiments with 308 and 356 series}

Table 6 exhibits the results of chemical analyses from the materials obtained in the filtering experiments for the 308 and 356 series alloys.

\subsubsection{6 series alloys}

The results of the experiments based on the 356 alloy (aluminum-7\%silicon) show the effect of manganese on the iron removal filtering. The addition of $0.6 \%$ manganese, maintaining the filtering temperature practically constant, caused a reduction in the iron content from $1.12 \%$ to $0.37 \%$. In the $3561 \mathrm{~F} 6 \mathrm{M}$ alloy, $\mathrm{Al}_{15}(\mathrm{Fe}, \mathrm{Mn})_{3} \mathrm{Si}_{2}$ substitutes alumi- 
Table 7 Manganese concentrations before and after filtering for sample 3561F6M.

\begin{tabular}{ccccc}
\hline Test & $\begin{array}{c}\text { Temp. } \\
\left({ }^{\circ} \mathrm{C}\right)\end{array}$ & $\begin{array}{c}\text { Initial Mn } \\
(\%)\end{array}$ & $\begin{array}{c}\text { Final Mn } \\
(\%)\end{array}$ & $\begin{array}{c}\text { Removal of Mn } \\
(\%)\end{array}$ \\
\hline 3561 F6M & 640 & 0.61 & 0.16 & 73.0 \\
\hline
\end{tabular}

Table 8 Copper concentrations before and after filtering.

\begin{tabular}{cccc}
\hline Alloy & $\begin{array}{c}\text { Temp. } \\
\left({ }^{\circ} \mathrm{C}\right)\end{array}$ & $\begin{array}{c}\text { Initial } \mathrm{Cu} \\
(\%)\end{array}$ & $\begin{array}{c}\text { Final } \mathrm{Cu} \\
(\%)\end{array}$ \\
\hline $3082 \mathrm{~F}$ & 635 & 3.70 & 3.90 \\
$3081 \mathrm{~F}$ & 625 & 3.35 & 3.78 \\
$3081 \mathrm{~F} 7$ & 618 & 3.10 & 3.82 \\
\hline
\end{tabular}

num as the primary phase. Hence, there is the possibility of iron removal provided that the temperature is reduced until the nearest point to the eutectic trough. Under these conditions, a phase containing manganese and iron precipitates in the same stoichiometric proportion and one can expect the reduction in the content of iron followed by an equal reduction in the content of manganese. As it will be seen later, the content of manganese was effectively reduced.

Table 7 shows the change in the manganese content before and after the filtering step. There was an effective reduction in the manganese and it would be caused by the fact that the $\mathrm{Al}_{15}(\mathrm{Fe}, \mathrm{Mn})_{3} \mathrm{Si}_{2}$ phase has manganese and iron at the same proportion.

\subsubsection{8 series alloy}

As the experiments were performed at temperatures in the $635-618^{\circ} \mathrm{C}$ range, the precipitation of primary phases containing iron and manganese was expected. Similar to the precipitation with the $3561 \mathrm{~F} 6 \mathrm{M}$ alloy, the favoring of the precipitation of intermediate phases containing iron and manganese by the presence of copper was hypothesized.

Chemical analyses were performed in order to check the participation of copper in the filtered phases. These results, exhibited in Table 8, confirm that no considerable partition occurred between the copper in the liquid phase and in the intermediate phases, precipitated at the treatment temperature.

Analogously to the alloys based on the 356 alloy, the residual content of manganese was reduced compared to the initial content, as exhibited in Table 9, which indicates that manganese is present in the filtered intermediate phases.

\subsection{Microstructural analysis}

All the experiments in which the content of iron was reduced by the filtering process coincided with dross forming at the bottom of the crucible. The amount of this dross is linearly proportional to the yield of the filtering process. Thus, part of the material precipitated from the liquid phase, at the filtering temperature, segregates to the lower regions of the crucible. Hence, the filtering process generated three samples: first, the filtered metal; second, the material retained in the filter and third, the material sedimented at the bottom of the crucible.

The amount of low-iron aluminum recovered after the filtering process depends on the initial iron concentration. For
Table 9 Manganese concentrations before and after filtering for 308 series.

\begin{tabular}{lccc}
\hline Alloy & $\begin{array}{c}\text { Temp. } \\
\left({ }^{\circ} \mathrm{C}\right)\end{array}$ & $\begin{array}{c}\text { Initial Mn } \\
(\%)\end{array}$ & $\begin{array}{c}\text { Final Mn } \\
(\%)\end{array}$ \\
\hline $3082 \mathrm{~F}$ & 635 & 0.30 & 0.10 \\
$3081 \mathrm{~F}$ & 625 & 0.14 & 0.08 \\
$3081 \mathrm{~F} 7 \mathrm{M}$ & 618 & 0.70 & 0.20 \\
\hline
\end{tabular}

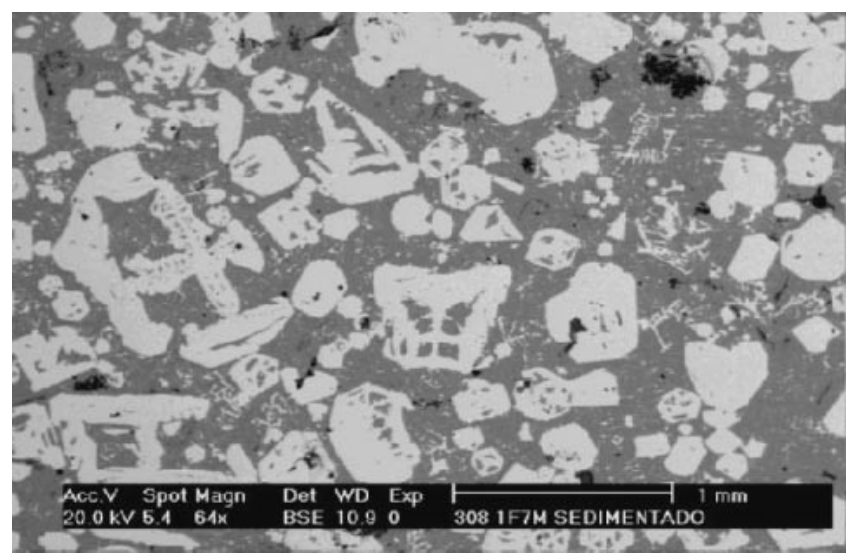

Fig. 2 Microstructure of the sample from sedimented material in the filtering process of $3081 \mathrm{~F} 7 \mathrm{M}$ alloy. Presence of faceted coarse crystals.

Table 10 Results of semi-quantitative EDS analysis of sedimented phase.

\begin{tabular}{ccc}
\hline Element & At\% & Mass\% \\
\hline $\mathrm{Al}$ & 70.35 & 57.77 \\
$\mathrm{Si}$ & 9.34 & 7.98 \\
$\mathrm{Mn}$ & 11.95 & 19.98 \\
$\mathrm{Fe}$ & 7.64 & 12.99 \\
$\mathrm{Cu}$ & 0.41 & 0.79 \\
\hline Total & 100.0 & 100.0
\end{tabular}

an alloy with $1 \%$ initial iron, the amount of refined aluminum recovered is about $80-85 \%$. Hence, 15 to $20 \%$ of the initial aluminum mass is lost in the sedimented dross and in the filter.

3.3.1 Material sedimented at the bottom of the crucible

Figure 2 shows the microstructural aspect of the material sedimented and retained at the bottom of the crucible. Relatively large, faceted, hexagonal phases can be seen. The size of the intermediate phases, rich in iron, is approximately $0.5 \mathrm{~mm}$, i.e., the same magnitude of the pores of the filters used. This type of microstructure was observed in all samples. Thus, the crystallization of a primary faceted intermediate phase occurs in the liquid during the cooling, due to the addition of manganese. This primary phase presents the shape of hexagonal particles about $0.5 \mathrm{~mm}$ or dendrites, keeping the solid faceted character.

Quantitative EDS experiments were performed with these sedimented intermediate phases and the mean results are exhibited in Table 10, suggesting that the sedimented phase is $\mathrm{Al}_{15}(\mathrm{Fe}, \mathrm{Mn})_{3} \mathrm{Si}_{2}$, containing also a small amount of copper in solution. The results of quantitative EDS are close to the stoichiometry of the $\mathrm{Al}_{15}(\mathrm{Fe}, \mathrm{Mn})_{3} \mathrm{Si}_{2}$ phase, strongly indicating the precipitation of this phase. 


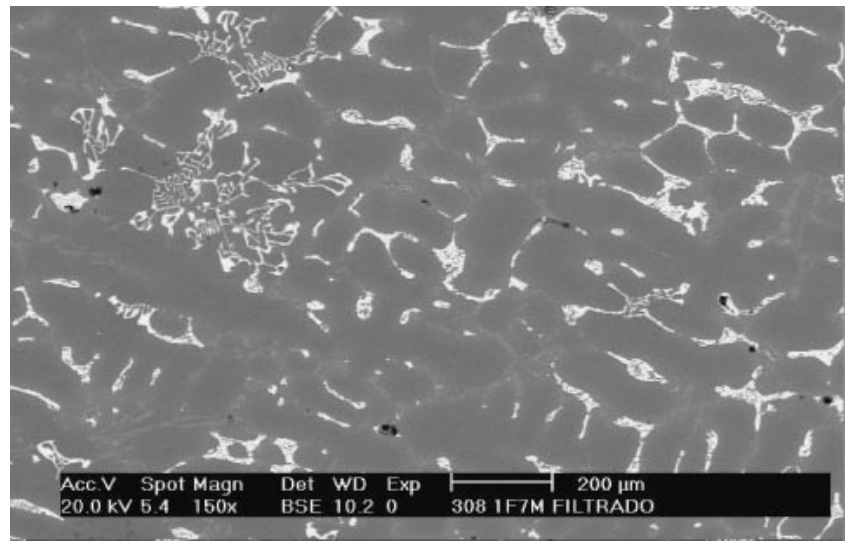

Fig. 3 Microstructure of the sample from filtered material of $3081 \mathrm{~F} 7 \mathrm{M}$ experiment. Dendrites of primary aluminum and interdendritic eutectic.

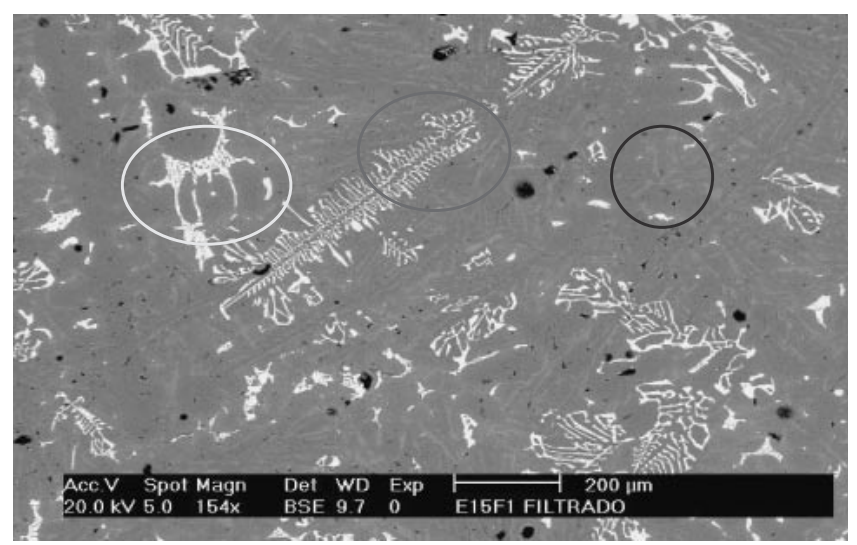

Fig. 4 Aspect of the interdendritic region showing three eutectic constituents for the E15F95S16M alloy.

The same precipitate aspect was observed for the sedimented material from the 3561F6M alloy. Similarly, the spectrum of micro-region analysis by EDS showed the presence of the $\mathrm{Al}_{15}(\mathrm{Fe}, \mathrm{Mn})_{3} \mathrm{Si}_{2}$ phase.

\subsubsection{Filtered material}

The microstructure of the filtered material from the 3081F7M alloy is indicated in Fig. 3. The presence of primary aluminum dendrites and interdendritic eutectic constituent can be observed.

In the E15F95S16M alloy, the interdendritic region primarily presents three eutectic constituents, as exhibited in larger scale in Fig. 4. Coarse lamella-shaped precipitates of the intermediate phase $\beta$ ( $\mathrm{Al}_{5} \mathrm{FeSi}$ ), typical of cast alloys contaminated with iron, are not observed.

Figure 5 exhibits a fishbone-type microstructure of the $\mathrm{Al}+\mathrm{Al}_{15}(\mathrm{Fe}, \mathrm{Mn})_{3} \mathrm{Si}_{2}$ eutectic in detail. The EDS spectrum of a particle from a fishbone-type $\mathrm{Al}+\mathrm{Al}_{15}(\mathrm{Fe}, \mathrm{Mn})_{3} \mathrm{Si}_{2}$ eutectic presented characteristic peaks of aluminum, silicon, iron, manganese and copper, indicating that the phase formed is $\mathrm{Al}_{15}(\mathrm{Fe}, \mathrm{Mn})_{3} \mathrm{Si}_{2}$.

Further analysis of the field shown in Fig. 4 indicates the presence of a eutectic region with three phases, as shown in Fig. 6. The EDS spectrum shows that the lighter phase formed has peaks of aluminum and copper, thus identifying the phase as $\mathrm{Al}_{2} \mathrm{Cu}$.

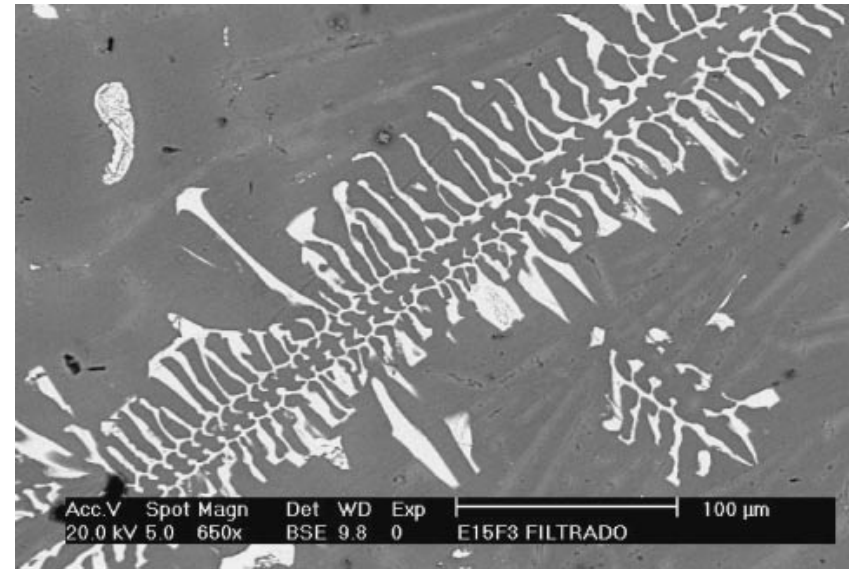

Fig. 5 Fishbone-type $\mathrm{Al}+\mathrm{Al}_{15}(\mathrm{Fe}, \mathrm{Mn})_{3} \mathrm{Si}_{2}$ eutectic in detail.

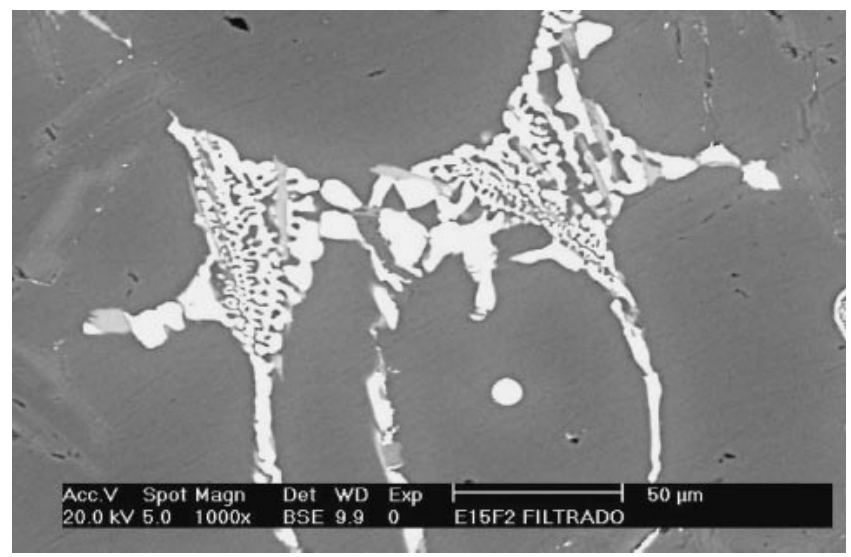

Fig. 6 Region containing $\mathrm{Al}+\mathrm{Cu}_{2} \mathrm{Al}+\mathrm{Mg}_{2} \mathrm{Si}$ phases in detail.

However, a light gray phase can be noted along the particles of the light phase, through a more critical analysis of Fig. 6. This observation indicates the presence of a ternary eutectic. The EDS spectrum of this phase evidences peaks of magnesium and silicon. Hence, the data suggests that the eutectic is $\mathrm{Al}+\mathrm{Cu}_{2} \mathrm{Al}+\mathrm{Mg}_{2} \mathrm{Si}$. The identified peaks of aluminum and copper are related to the small size of the particles analyzed.

\subsubsection{Material retained inside the filter}

The pores of the filter were effectively sealed by the particles of the intermediate phase, preventing the passage of aluminum. In regions unobstructed by intermediate phase particles, the filter is very clean. Aluminum containing solid particles penetrates the filter to a certain depth; in the lower region of the filter practically no pores were obstructed. Two regions bounded by a threshold region can be distinguished in the material retained in the filter. The borderline is visible by gross visual examination, following the metallographic preparation. The material presents a hybrid microstructure, between the sedimented material and the filtered material above this borderline. Below the borderline the material has a structure similar to the filtered material. Thus, the intermediate phases are effectively imprisoned with dimensions similar in size to the pores of the filter. This material accumulates and blocks the passage of aluminum through the 


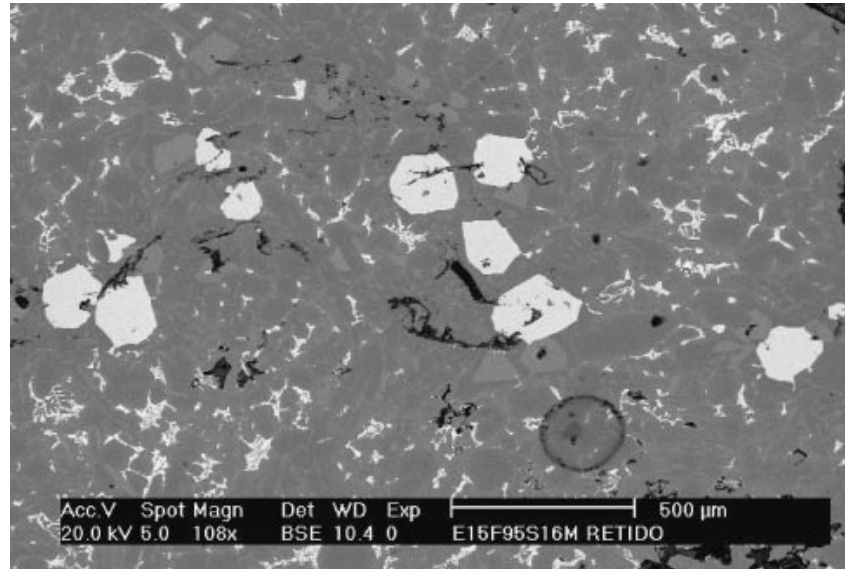

Fig. 7 Typical microstructure of the material retained in the filter in the upper part for E15F95S15M alloy, where the great dimension particles of the intermediate phase are retained.

Table 11 Results of semi-quantitative EDS analysis of interdendritic white phase.

\begin{tabular}{ccc}
\hline Element & At\% & Mass\% \\
\hline $\mathrm{Al}$ & 69.24 & 56.71 \\
$\mathrm{Si}$ & 10.87 & 9.26 \\
$\mathrm{Mn}$ & 5.99 & 9.99 \\
$\mathrm{Fe}$ & 11.84 & 20.07 \\
$\mathrm{Cu}$ & 2.06 & 3.97 \\
\hline Total & 100.0 & 100.0 \\
\hline
\end{tabular}

pores. Below this line, where coarse particles concentrate, there is a layer of filtered and solidified aluminum.

Figure 7 exhibits the typical microstructure of the material retained in the filter above the threshold region described. Quantitative EDS analysis was carried out for one of the intermediate phases with dimensions similar to the ones observed in the sedimented material. The results presented in Table 11 show a composition very similar to the values observed in the sedimented material. Thus, the identified phase is $\mathrm{Al}_{15}(\mathrm{Fe}, \mathrm{Mn})_{3} \mathrm{Si}_{2}$.

The material is morphologically identical to the filtered material below the region where particles of $\mathrm{Al}_{15}(\mathrm{Fe}$, $\mathrm{Mn})_{3} \mathrm{Si}_{2}$, with dimensions of approximately $50 \mu \mathrm{m}$ are concentrated. Hence, the material is basically free of the coarse particles of $\mathrm{Al}_{15}(\mathrm{Fe}, \mathrm{Mn})_{3} \mathrm{Si}_{2}$. Thus, the morphology is basically constituted of dendrites of aluminum containing interdendrite regions with the presence of eutectic constituents.

The eutectic containing silicon appeared in all alloys. However, as a result of the contrast of the backscattered electrons used, this phase is not finely distinguished from aluminum, as both have a similar atomic weight. In Fig. 8, the presence of a darker phase, corresponding to silicon, can be noted, as confirmed by EDS spectrum. The eutectic constituent has a divorced eutectic morphology typical of

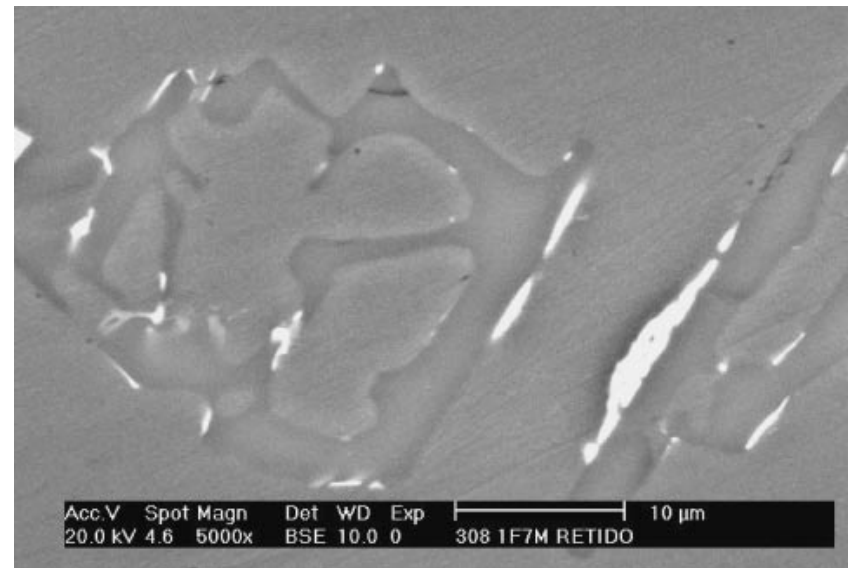

Fig. 8 Typical aspect of the eutectic region containing $\mathrm{Al}$ (matrix) Si (dark phase with relief aspect) and needles of $\mathrm{Al}_{15}(\mathrm{Fe}, \mathrm{Mn})_{3} \mathrm{Si}_{2}$.

aluminum cast alloys. There is the remarkable presence of lamellae of $\mathrm{Al}_{15}(\mathrm{Fe}, \mathrm{Mn})_{3} \mathrm{Si}_{2}$ in this eutectic region, suggesting a ternary eutectic, $\mathrm{Al}+\mathrm{Al}_{15}(\mathrm{Fe}, \mathrm{Mn})_{3} \mathrm{Si}_{2}+\mathrm{Si}$.

\section{Conclusions}

The following conclusions has been obtained, under the experimental conditions of this study:

(1) The process of aluminum filtering in order to reduce the content of iron is possible provided by the use of aluminum-silicon alloys, with additions of manganese followed by the reduction of the temperature until the crystallization field of the primary phases containing iron.

(2) Each alloy needs an adequate manganese content (by addition of it) in order to obtain a higher efficiency of iron removal. The manganese content is related to the iron content of the alloy.

(3) Removal of iron was performed by the precipitation of the intermediate phase $\mathrm{Al}_{15}(\mathrm{Fe}, \mathrm{Mn})_{3} \mathrm{Si}_{2}$, for the 308 and 356 alloys and for the experimented alloys of this study.

(4) Removal of iron occurs in two steps: a sedimentation step is followed by the filtering step.

\section{REFERENCES}

1) P. Liu, T. Thorvaldsson and G. L. Dunlop: Materials Science and Technology. 2 (1986) 1009-1018.

2) G. Davignon, A. Serneels, B. Verlinden and L. Delaey: Metallurgical and Materials Transactions A. 27A (1996) 3357-3361.

3) V. M. Grigorenko, V. A. Popov and A. A. Ofengenden: Sovjet NonFerrous Metals Research. (1977) 281-282.

4) A. Flores, J. Escobedo, J. Mendez and M. Mendez: Light Metals 1992; ed. by E. R. Cutshall (The Minerals, Metals and Materials Society, 1992) pp. 845-850.

5) H. M. Van der Donk, G. H. Nijhof and C. A. M. Castelijns: Proc. 3rd International Symposium on Recycling of Metals and Engineered Materials, ed. by P. B. Queneau and R. D. Peterson (The Minerals, Metals e Materials Society, 1995), pp. 651-661. 